risks, the DMHEF aims to minimise the amount of data that is shared (saving health professionals time and encouraging completion), without compromising any potential benefit to creditors, money advisors, or the individual with debt and mental health problems. A mixed-methods evaluation has now been funded in real-life creditor, advice and health settings to: ascertain whether the DMHEF informs effective decision-making; describe any barriers to its use and correct implementation; and identify what mental health education creditor and money advice organisations need.

\section{Funding}

The study was funded by the Money Advice Trust's research grant programme. C.F. has received research and educational materials grants from the following organisations: the Money Advice Trust, Finance and Leasing Association, Friends Provident Foundation, and Financial Services Authority. S.T. has worked on a research grant provided by the Money Advice Trust.

\section{About the authors}

Chris Fitch, Research Fellow, and Robert Chaplin, Research Fellow, work at the Royal College of Psychiatrists' Research Unit, London. Simon Tulloch
Research and Service Development Officer, Academic Unit, works at the Newham Centre for Mental Health, East London NHS Foundation Trust.

\section{References}

1 Office for National Statistics. The Social and Economic Circumstances of Adults with Mental Disorders. TSO (The Stationery Office), 2002.

2 Department of Trade and Industry. Tackling Over-Indebtedness. Department of Trade and Industry, 2006

3 Mind. In the Red: Debt and Mental Health. Mind, 2007

4 Money Advice Liaison Group. Good Practice Guidelines: Debt Management and Debt Collection in Relation to People with Mental Health Problems. MALG, 2007.

5 Edwards S. In Too Deep: CAB Clients' Experiences of Debt. Citizens Advice Bureau, 2003.

6 Royal College of Psychiatrists. Debt and mental health - resources for health and social care workers. Royal College of Psychiatrsits, 2010 (http://www.rcpsych.ac.uk/debt).

7 Harris M. Psychiatric conditions with relevance to fitness to drive. Adv Psychiatr Treat 2000; 6: 261-9.

8 MacFarlane AB. Medical evidence in the Court of Protection. Psychiatr Bull 1985; 9: 26-8.

9 Killoughery M. Disability and incapacity benefits. The role that doctors play. Psychiatr Bull 1999; 23: 260-3.

\title{
Recreational drugs and health information provided in head shops
}

\author{
Divina Pillay, ${ }^{1}$ Brendan D. Kelly ${ }^{1}$
}

The Psychiatrist (2010), 34, 100-102, doi: 10.1192/pb.bp.108.024646

${ }^{1}$ University College Dublin, Ireland Correspondence to Brendan D. Kelly (brendankelly35@gmail.com)
Aims and method To determine which recreational drugs are most readily offered in 'head shops', and what safety information is provided; and determine sales assistants' knowledge about the mental health complications of cannabis. Researchers surveyed ten head shops in Dublin.

Results Sales assistants in all head shops described their products as legal and safe. Overall, 50\% stated cannabis was generally not harmful, although 50\% stated it might cause depression and $60 \%$ stated it might cause psychosis in susceptible people. Salvia was available in $90 \%$ of outlets, although sales assistants in $78 \%$ warned about its potency.

Clinical implications Legal, psychoactive drugs, some of which are banned in other jurisdictions, are readily available in Dublin head shops. Enhanced awareness and effective regulation are required.

Declaration of interest None.
'Head shops' are retail outlets that sell legal recreational drugs, herbal mixtures which can be smoked, and various paraphernalia which can be used for the growth and consumption of cannabis. Head shops do not sell cannabis, which is illegal in the Republic of Ireland, the UK and many other jurisdictions.

Head shops first came to prominence in the USA in the 1960s, with the opening of the Psychedelic Shop on Height 
Street in San Francisco by Ron Thelin, a US army veteran. ${ }^{1}$ The Psychedelic Shop not only sold paraphernalia related to the consumption of hallucinogenic drugs but also provided facilities for various forms of meditation, consistent with the shop's counter-culture ethos. Although the Psychedelic Shop closed its doors after less than 2 years of operation, it had started a trend that resulted in head shops opening in most towns and cities across the USA over the following five decades; many of these are located near supermarkets, schools or record shops. ${ }^{2}$

The first head shop in the Republic of Ireland opened in 2000 , and by 2007 there were 24 head shops operating in towns and cities across the country. ${ }^{3}$ These outlets sell a wide variety of products ranging from rolling papers, pipes and lighters, to powerful, legal psychoactive substances and recreational drugs. In the UK, it is estimated that there are 200 head shops supporting a UK industry estimated to be worth £10 million annually, not including international sales through websites. ${ }^{4}$

The presence of so many head shops in the Republic of Ireland, the UK and elsewhere raises two specific areas of concern relating to the quality and effects of recreational drugs and herbal mixtures available, and the extent to which these outlets inadvertently promote or facilitate cannabis use.

In the first instance, the quality and effects of substances sold in head shops are likely to be difficult to establish, not least because their preparation and sale are generally unregulated. There is some evidence that products containing the hallucinogen salvia divinorum present particular cause for concern. Salvia divinorum is a potent plant hallucinogen that is available both through internetbased suppliers and head shops. ${ }^{5}$ One analysis of five herbal products containing Salvia divinorum found substantial discrepancies between advertised and actual contents of salvinorin A (a psychoactive compound found in Salvia divinorum), raising the potential risks of both misuse and overdose. $^{6}$

In November 2008, the Republic of Ireland's police force raided 22 head shops throughout the Republic of Ireland in order to see if their products contained illicit substances. $^{7}$ In late November 2008, the Republic of Ireland's Minister for Health and Children announced that she was considering banning certain stimulant drugs sold in such shops. ${ }^{8}$

The second area for concern is that it is difficult to establish the precise extent to which head shops inadvertently promote or facilitate cannabis use. Head shops tend to sell a wide array of paraphernalia that can be used for cannabis consumption (pipes, bongs, rolling papers, scales) and cultivation (manuals, trays, heaters, lights, tents). There is a growing body of evidence that cannabis use is associated with a range of mental illnesses including depression, anxiety ${ }^{9}$ and schizophrenia. ${ }^{10}$ There is a paucity of information, however, on the extent to which the operators of head shops accept these findings or use them to inform their sales practices.

Our study aimed to, first, determine which recreational drugs were most readily offered to customers in head shops, and what information was provided about the safety of such products; and, second to determine sales assistants' knowledge of the potential mental health complications of cannabis use.

\section{Method}

Data were gathered using participant observation, an ethnographic technique in which the researcher is a direct participant in the phenomenon being studied. ${ }^{11}$ Single researchers visited ten arbitrarily chosen head shops in Dublin.

In each head shop, the researcher said to the sales assistant: 'I haven't used anything like this before. Is there anything you would recommend?' When offered a specific product, the researcher asked: 'Is this legal? Is this harmful?' The researcher then asked: 'I know cannabis is illegal, but can you tell me is cannabis harmful? Could cannabis make me depressed? Could cannabis make me psychotic or lose my mind?' Finally, the researcher asked to see products containing salvia and noted whether or not the sales assistant offered any advice about the potency or potential harmfulness of salvia. Researchers recorded their findings immediately after leaving the head shops, using a proforma designed for this purpose.

We performed a careful risk assessment prior to commencing our study, and agreed to visit head shops during daylight hours only; to inform each other which head shops we were visiting; to telephone each other upon entering and leaving each head shop; and to immediately leave any head shop in which we sensed any form of threat.

Participant observation is an especially useful way to collect data about social practices that may change significantly in the context of a formal study. ${ }^{11-13}$ Participant observation can involve a wide range of contrasting methodologies, some of which involve researchers actively immersing themselves in specific contexts (e.g. pretending to have a mental illness and covertly presenting to a hospital), whereas others involve observing events or information in the public domain with minimum interference (e.g. skating on an ice-rink and overtly observing skaters' awareness of safety rules).

The precise requirements for, and components of, ethical approval will vary depending on the precise 'participant observation' methodologies involved in any given study. Detailed engagement with a local research ethics committee can help greatly with the elucidation of these issues. ${ }^{13}$ We discussed our study with our local research ethics committee and conducted our study in accordance with their requirements, and with the agreement of the relevant insurers.

\section{Results}

In all ten head shops, sales assistants readily recommended legal, recreational psychoactive substances to researchers. The products most commonly recommended were Smoke (five outlets), Spice Gold (two), Zohai (two) and Chronic Joint (one). Of these, only two packets displayed a list of contents: Spice Gold and Smoke (which was described on its packet as an incense product to be burned rather than smoked). All sales assistants $(100 \%, n=10)$ described these products as both legal and safe. Regarding cannabis, $50 \%$ $(n=5)$ of sales assistants stated that cannabis was generally 
not harmful, $50 \%(n=5)$ of sales assistants stated that cannabis might cause depression and 60\% $(n=6)$ said cannabis might cause psychosis in susceptible people.

Salvia was available to buy in $90 \%(n=9)$ of head shops, and in $78 \%(n=7)$ of these outlets the sales assistants provided warnings about its potency and/or potential harmfulness. These sales assistants all suggested that salvia should only be used in a safe place and when accompanied by someone who was not using it. A similar warning is printed on the packages of the salvia preparations available in the head shops.

\section{Discussion}

This study found that sales assistants in head shops in Dublin recommend specific, legal, recreational psychoactive substances to customers and describe these products as both legal and safe. The chief strength of this study is the fact that this is the first study, to our knowledge, to examine systematically the products and information offered to customers in head shops. Limitations include the exclusion of outlets outside Dublin and the absence of laboratory analysis of the contents of recreational drugs offered to researchers. This study relied on the knowledge and advice of sales assistants in head shops, rather than managers or owners, who might be more knowledgeable; this was a conscious choice at the stage of research design, aimed at recreating the likely experiences of average customers in head shops.

The ready availability of salvia in head shops presents particular cause for concern, notwithstanding the fact that the majority of sales assistants provided warnings about the potency of the drug. This concern stems not only from the demonstrated discrepancies between advertised and actual contents of salvinorin A, but also the presence of various additional adulterants in certain salvia preparations, which further highlights the unreliable quality of these products. ${ }^{6}$ The intense psychoactive potency of salvia has become a focus of attention in many countries in recent years, and products containing salvia have been banned in several parts of the USA: in Florida, for example, possession or sale of salvia is a felony punishable by 15 years in prison. ${ }^{14}$ Other states, such as California, have taken a less aggressive approach, making it a misdemeanour to sell salvia to minors. ${ }^{14}$

It is exceedingly difficult to establish whether or not head shops inadvertently promote cannabis use. We did not seek to buy cannabis in any of the head shops we visited, and nor was cannabis offered to us. Shop assistants showed significant awareness of the mental health problems associated with cannabis, but our results do not provide any clear indication about whether or not these outlets might still, inadvertently, facilitate cannabis use, through, for example, the sale of pipes, bongs, etc. A more detailed, differently designed study is required in order to elucidate this matter further, possibly involving both quantitative and qualitative methodologies, aimed at elucidating patterns of substance misuse over time among head shop customers.

Overall, our results suggest a need for enhanced awareness of the existence of head shops and the potency of the products they sell, especially among emergency medicine and mental healthcare providers who may see individuals following the use of such substances. There is also a need for pragmatic, effective regulation of such outlets, in order to ensure that potent, psychoactive products are not sold to minors or in excessive quantities. There is a particular need to review the safety of salvia and possibly reconsider the ready availability of saliva in head shops. There is also a need routinely to assess the contents of all products sold in head shops, so as to ensure, insofar as possible, that they are safe for human consumption.

\section{About the authors}

Divina Pillay is a registrar in psychiatry and Brendan D. Kelly is a senior lecturer in psychiatry, University College Dublin, Ireland.

\section{References}

1 Taylor M. Obituary: Ron Thelin. San Francisco Chronicle 1996; 22 March.

2 Press RM. Nationwide drive against 'head shops' runs into a federal court snag. Christian Science Monitor 1980; 17 December.

3 Clark S. Rise of the head shops. Sunday Business Post 2007; 16 December.

4 McCandless D. Exotic, legal highs become big business as "headshops' boom. Guardian 2006; 9 January.

5 Prisinzano TE. Psychopharmacology of the hallucinogenic sage Salvia divinorum. Life Sci 2005; 78: 527-31.

6 Wolowich WR, Perkins AM, Clenki JJ. Analysis of the psychoactive terpenoid salvinorin A content in five Salvia divinorum herbal products. Pharmacotherapy 2006; 26: 1268-72.

7 Lally C. Gardai raid 22 'head shops' suspected of selling illegal drugs. Irish Times 2008; 7 November.

8 Kelly O. 'Head shop' products face ban. Irish Times 2008; 1 December.

9 Patton GC, Coffey C, Carlin JB, Degenhardt L, Lynskey M, Hall W. Cannabis use and mental health in young people: cohort study. BMJ 2002; 325: 1195-8.

10 Castle D, Murray R. Marijuana and Madness: Psychiatry and Neurobiology. Cambridge University Press, 2004.

11 Spradley JP. Participant Observation. Harcourt Brace Jovanovich, 1980.

12 Bulmer M. Social Research Ethics. Macmillan, 1982.

13 Moore L, Savage J. Participant observation, informed consent and ethical approval. Nurse Researcher 2004; 9; 58-69.

14 Sack K, McDonald B. Popularity of a hallucinogen may thwart its medical uses. New York Times 2008; 9 September. 